\title{
REFORMING HIGHER EDUCATION TEACHING PRACTICES IN AFRICA
}

Critical thinking - the process of questioning and learning with an open mind - is considered one of the most important outcomes of a contemporary university education, a crucial skill for graduate participation in the global 'knowledge economy'. Thanks to innovative research from University College London, UK together with researchers from the University of Botswana, the University of Cape Coast in Ghana, and Strathmore University in Kenya, universities across subSaharan Africa are now making changes to their teaching practices to support the development of their students' critical thinking skills.

\section{THE CHALLENGE}

The new development challenges facing countries in sub-Saharan Africa - and elsewhere - call for individuals with demonstrable critical thinking skills. However, despite a large body of literature looking at ways in which academic experiences at university can positively influence the development of student critical thinking skills, current evidence rests largely on research conducted in the USA, UK, and Australia. There is a noticeable lack of research and evidence to inform these debates in the African context.

\section{THE RESEARCH}

The 'Pedagogies for Critical Thinking: Innovation and Outcomes in African Higher Education' project examined the impact of teaching reforms in 14 universities across Botswana, Ghana, and Kenya. Using a mixed methods approach (a longitudinal study of student 'gains' in critical thinking over a two-year period and a qualitative investigation of the teaching and learning environment), researchers wanted to understand how different teaching styles affected the development of critical thinking skills,
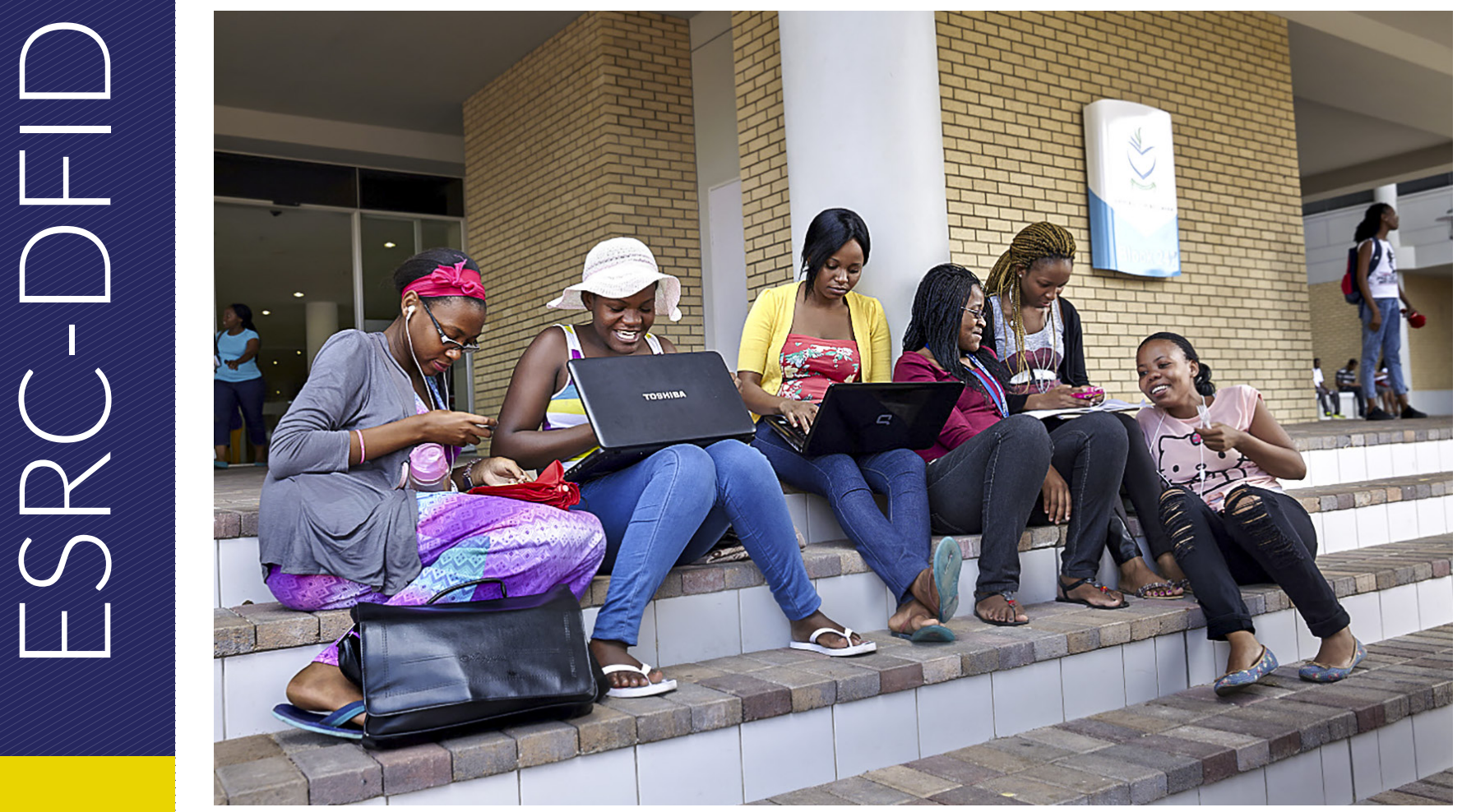

Photo: A group of students sit together outside a University in Botswana. Credit: Marc Shoul/Panos Pictures 
and how universities in Africa respond to processes of pedagogical change.

Measuring critical thinking skills using an adapted version of the 'Collegiate Learning Assessment' (a test undertaken by students at the start of their undergraduate course and then another two years later), the study found that three universities in particular supported significant improvements in the critical thinking skills of their students. They were found to have:

- Enabled a shared teaching culture in which faculty members privileged independent student learning;

- Created a learning environment in which students were exposed to a variety of viewpoints and perspectives;

- Ensured critical thinking was a required skill across the curriculum;

- Created a culture of pedagogical improvement, providing regular ongoing development for teaching staff;

- Restructured assessment formats so as to better align with teaching approaches; and

- Provided teaching staff with sufficient time to discuss and improve their practices, in order to foster pedagogical change.

\section{THE IMPACT}

Following the dissemination of research in all three countries, many of the participating universities are considering ways to reform their teaching practices and processes to better prepare lecturers in the skill of fostering critical thinking.

In Kenya, the Commission for University Education has now incorporated critical thinking into its national work and is supporting universities in adapting their curricula. Mwenda Ntarangwi, CEO, explained:

This research has supported one of the bold moves taken [by the Government of Kenya] to introduce a competence-based curriculum that aims at producing students with requisite skills and competencies that meet the needs of a changing society propelled by a knowledge economy. [It is] particularly useful for supporting this change where learning is herewith active and interactive as the learner takes on a larger role in the process of learning as the teacher's role increasingly becomes facilitative. These critical thinking skills are a must for all Kenyan students, not just a preserve of a few who may have access to select institutions.
Some Kenyan universities have also explicitly prioritised critical thinking within institutional structures. For example, one private university in Nairobi has recently adopted critical thinking as a key dimension in its curricular review at an institutional level, while another is incorporating aspects of critical thinking into its staff development programme.

In Botswana, the project inspired one participating university to organise a seminar for faculty and staff that focused on the importance of critical thinking skills for employment. Another institution is preparing to overhaul its process for evaluating teaching quality (a critical component of the academic promotions policy), to better support the kinds of institutional characteristics highlighted by the study.

In Ghana, there is evidence that lecturers at the public universities involved in the study have embedded critical thinking into their teaching approaches since the research took place. However, in some cases the success of these innovations is restricted by large class sizes, indicating that systemic change across the university system is needed.

The 'Pedagogies for Critical Thinking' research has shown the success of infusing critical thinking across the curriculum. It is providing an important evidencebased contribution to a critically overlooked aspect of university quality in the region.

\section{FURTHER READING}

Rolleston, C.; Schendel, R. and Grijalva Espinosa, A.M. (2019) 'Assessing "Approaches to Learning" in Botswana, Ghana and Kenya', Research in Comparative and International Education 14.1: 118-140

Schendel, R.; McCowan, T.; Rolleston, C.; Tabulawa, R.; Adu-Yeboah, C. and Omingo, M. (2019) Pedagogies for Critical Thinking: Implications of Project Findings for Higher Education Policies and Practices in Ghana, Kenya and Botswana, London: University College London (UCL) Institutional Research Information Service (IRIS)



Pedagogies for Critical Thinking: Innovation and Outcomes in African Higher Education

The research team was funded by the ESRC-DFID Raising Learning Outcomes in Education Systems Research Programme led by Tristan McCowan (University College London, UK) and Rebecca Schendel (University College London, UK and Boston College, USA). The research was carried out in partnership with Caine Rolleston (University College London, UK); Richard Tabulawa (University of Botswana); Christine Adu-Yeboah (University of Cape Coast, Ghana) and Mary Omingo (Strathmore University, Kenya).

\section{THE IMPACT INITIATIVE}

\section{For International Development Research}

The Impact Initiative seeks to connect policymakers and practitioners with the world-class social science research supported by the ESRC-DFID Strategic Partnership, maximising the uptake and impact of research from: (i) the Joint Fund for Poverty Alleviation Research, and (ii) the Raising Learning Outcomes in Education Systems Programme. We seek to identify synergies between these programmes and their grant holders, support them to exploit influencing and engagement opportunities, and facilitate mutual learning. The Impact Initiative is a collaboration between the Institute of Development Studies (IDS) and the University of Cambridge's Research for Equitable Access and Learning (REAL) Centre.

All content is available under the Open Government License v3.0, except where otherwise stated.



